\title{
BYOE: The Design and Operation of an Electric Motors Simulator
}

\section{Dr. Carl J. Spezia P.E., Southern Illinois University, Carbondale}

Carl J. Spezia is an Associate Professor in the Electrical Engineering Technology program in the Department of Technology at Southern Illinois University, Carbondale (SIUC). He joined the program in1998 as a Visiting Assistant Professor. He worked as a power systems engineer for electric utilities for eight years prior to seeking a career in higher education. He is a licensed Professional Engineer in Illinois. His industrial assignments included power system modeling, power systems protection, and substation design. He received his M.S. and Ph.D. from SIUC in 1991 and 2002, respectively. He teaches courses in electric power and machinery, industrial automation, and is the Program Coordinator. He has won departmental teaching honors three times in the last five years. His research interests include power systems economics, power markets, and electric energy management.

\section{Dr. Garth V. Crosby, Southern Illinois University, Carbondale}

Dr. Garth V. Crosby is an associate professor in the Technology Department at Southern Illinois University Carbondale. He obtained his M.S. and Ph.D. degrees from Florida International University in Computer Engineering and Electrical Engineering, respectively. Dr. Crosby's primary interests of research are wireless networks, wireless sensor networks, network security and active learning strategies for STEM. He has served as a reviewer for several conferences, magazines and journals publications, including IEEE INFOCOM, and IEEE Transactions on Systems, Man and Cybernetics. He is a senior member of the Institute of Electrical \& Electronics Engineers (IEEE), a member of the National Society of Black Engineers (NSBE), and Eta Kappa Nu. 


\title{
BYOE: The Design and Operation of an Electric Motors Simulator
}

\begin{abstract}
There are fundamental challenges in teaching a lab-intensive course in electric motors online. There are few simulators to choose from, and these are quite expensive. Therefore, the question was asked, "how do we teach electric motors in a way that is inexpensive for both the student and the institution?" To answer this question, an undergraduate student research project was designed and developed with funding from the university's Center of Undergraduate Research and Creative Activities. The objective of the project was to develop a user-friendly simulator that can be used to conduct electric motors (machines) experiments. This project resulted in the development of a customized educational simulator appropriate for use in the electric motors course. The instructor can use this simulator as a tool to teach his/her students various electric motors concepts in a visual way. Additionally, students can use this simulator at any time or place to reinforce important theoretical concepts by conducting the experiments and noting the results. The developers utilized a graphically-based set of virtual machines and instruments that produce results that closely approximates actual devices. This paper discusses the design, implementation and operation of the simulator. Results of a survey of a pilot group of students is presented. Additionally, a sample experiment that demonstrates the simulator's functionality is described. Finally, information pertaining to how to freely access the simulator is provided.
\end{abstract}

\section{Introduction}

Today's students enter technical program through many paths. Student access to technical education through online programs is increasing due to the flexibility of delivery that this type of educational experience provides. This delivery method is very attractive to adult learners with established careers and family responsibilities that prohibit regular on-campus attendance. However, a major obstacle to online delivery is providing laboratory experiences that are pedagogically equivalent to the traditional experience, that is, the manipulation of physical equipment in a campus laboratory facility.

This challenge has a number of possible solutions, especially when the laboratories involve simple circuit analysis experiments and the fundamentals of electronics. In these cases suitable miniaturized equipment and industry grade software are readily available. Commercial equipment suppliers provide affordable home lab kits and simulation software that can provide students with acceptable remote laboratory experiences ${ }^{1,2}$. Although, the online laboratory structure does need optimization for maximum student benefits ${ }^{3}$. However, for the experiments typical of an electric motors/machines course, the researchers did not find simulation software that was both suitable and affordable. Additionally, no portable lab kits were identified on the market. 
It must be noted that the online delivery of electric machines laboratory presents a special set of issues. Conventional electric machines labs usually consist of expensive and physically large ac/dc motors and generators with associated power supplies, loads and instrumentation. The machine power ratings can range from several hundred to thousands of watts, with larger machines giving more realistic results. In a typical electric motors experiment, students must locate and identify the appropriate equipment, make the correct electrical connections, read both analog and digital instrumentation and record the data. The preferred method of providing students with virtual machine lab experiences is through computer-based simulations ${ }^{4,5}$. These simulations give both face-to-face and online students the ability to view the performance of electric machinery without accessing the lab equipment.

The researchers were very keen on developing a software simulation that would facilitate the students' acquisition of specific skills that would allow them to satisfy the course learning objectives. This guided the researchers as they review commercial and open source machine simulation packages. It was determined that these generally focus on the mathematical models, with animations of the machine performance used to help students visualize the complex nature of electromagnetic power conversion ${ }^{6,7}$. These simulators allow users to modify parameters and instantaneously view the effects of the changes on machine performance characteristics. This simulation type, although instructive, eliminate some of the fundamental laboratory experiences that is considered pedagogically beneficial. These include reading a schematic diagram and converting it to a set of correct physical connections, adjusting power sources to prescribed values, and reading values from instrumentation. In the case of an electric machines lab these instruments may include both electrical and mechanical measurement devices. The lack of software tools that facilitated these skills development, and the desire to obtain this were key motivating factors for this project.

The researchers aim was to develop a virtual lab experience that mimics what exists in the physical labs. Learning from prior works that created computer-based simulations and data collection programs using LabVIEW to teach ac/dc machines in face-to-face labs ${ }^{8}$; a software simulation was developed. In this demonstration a solution to the online delivery of a lab intensive electric motors/machines course is presented. The ability of the simulator to output realistic results in close alignment with physical machines is highlighted. The demonstration consist of a prototype lab activity that allows students to connect a virtual machine's instruments and power supply, activate the experiment using power switches, adjust sources to achieve the desired results, and read both analog and digital instrument displays. Additionally, results of a survey assessing students' perception, attitude and the pedagogical effectiveness of the 'simulated lab' experience is presented. 


\section{Lab Preparation and Delivery in Face-to-Face Courses}

The face-to-face electric machines courses require students to complete several laboratory activities that illustrate and re-enforce topics of ac/dc machine theory and operation. Students perform experiments using fractional horsepower ac/dc motors and generators manufactured by Hampden Engineering Corporation using experiments developed by this company. Students perform these experiments at workstations that provide power supplies and a test bed for assembling machinery and making connections to instrumentation. Students complete short lab reports that include data analysis, discussion of results, and completion of a short quiz that includes multiple choice and short answer questions.

The program faculty wishes students in both the face-to-face and the online sections of the course to have similar experiences. Since online students cannot access the workstations remotely, program faculty members and undergraduate students explored methods for creating realistic lab simulations based on the existing lab content. The simulator development began with an analysis of the essential skills students should acquire in an electric motor lab experience.

The face-to-face lab activities require students to select the correct machines and instruments, wire the machines and instruments using provided schematic diagrams, and adjust instruments to collect electrical and mechanical measurements. Developers focused the software functionality on the experiences of correctly wiring machines and instruments, adjusting virtual instruments and reading values from meters. The simulator functionality should include the experience of adjusting voltage sources and activating power supplies and machines by correctly identifying and changing the position of switches and control knobs in the program. The central premise is that if these software criteria are satisfied, then the online students will experience, from a pedagogical perspective, the same labs as the face-to-face students using the actual machines.

Online students will access the experimental simulators through the learning management system. The simulator software consists of a series of executable files developed using LabVIEW. Students can run the executable files on their own computers. Utilizing this type of software delivery instead of a Web-based software solution gives students greater access compared to commercial solutions that are restricted to the number of accesses purchased by the institution. Once downloaded, students need not be concerned of losing data due to bad/slow internet connections. For assessment, students are required to complete a short quiz, with questions similar to those asked in the face-to-face experiment, and a brief lab report. 


\section{The Development and Operation of the Simulator}

The simulator team chose LabVIEW for the development tool. LabVIEW has a number of standard controls and indicators simulating meters and switches. The programs created custom controls based on these standard devices that more closely resemble those found on the physical lab equipment. The custom controls became the basis for developing simulated machines and instruments. Figure 1 shows the experimental setup for the first experiment in the program's dc machines course.

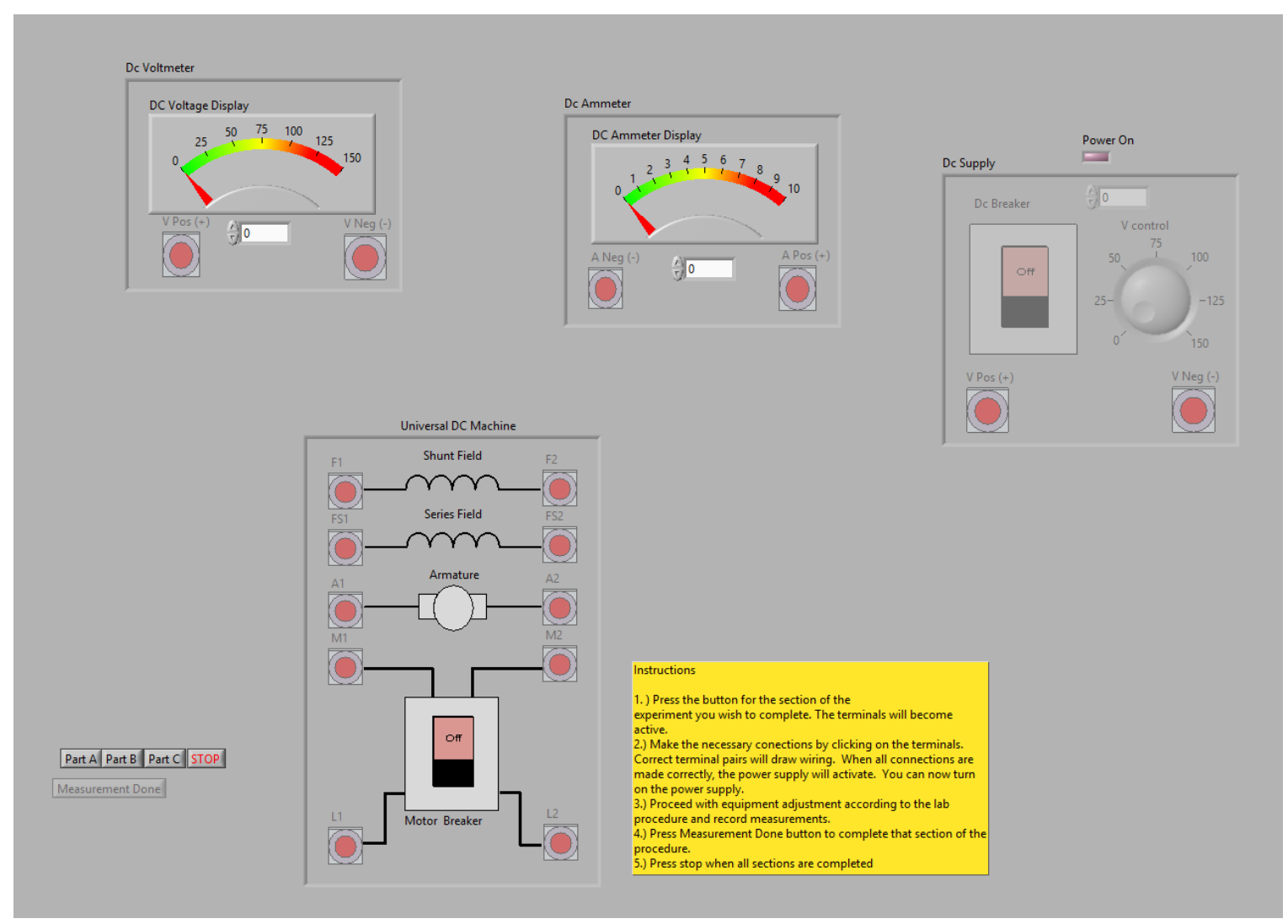

Figure 1. Lab 1 Simulator Showing Required Components, Terminals and Simulator Controls.

The connection points are custom controls base on a standard digital control (binary switch). A LabVIEW data structure called a cluster forms the dc power supply, universal dc machine, and the other instruments. These building blocks are reused in other simulator constructions. Using LabVIEW's predefined controls and indicators allowed developers to rapidly create user interfaces and the simulators functionality. 


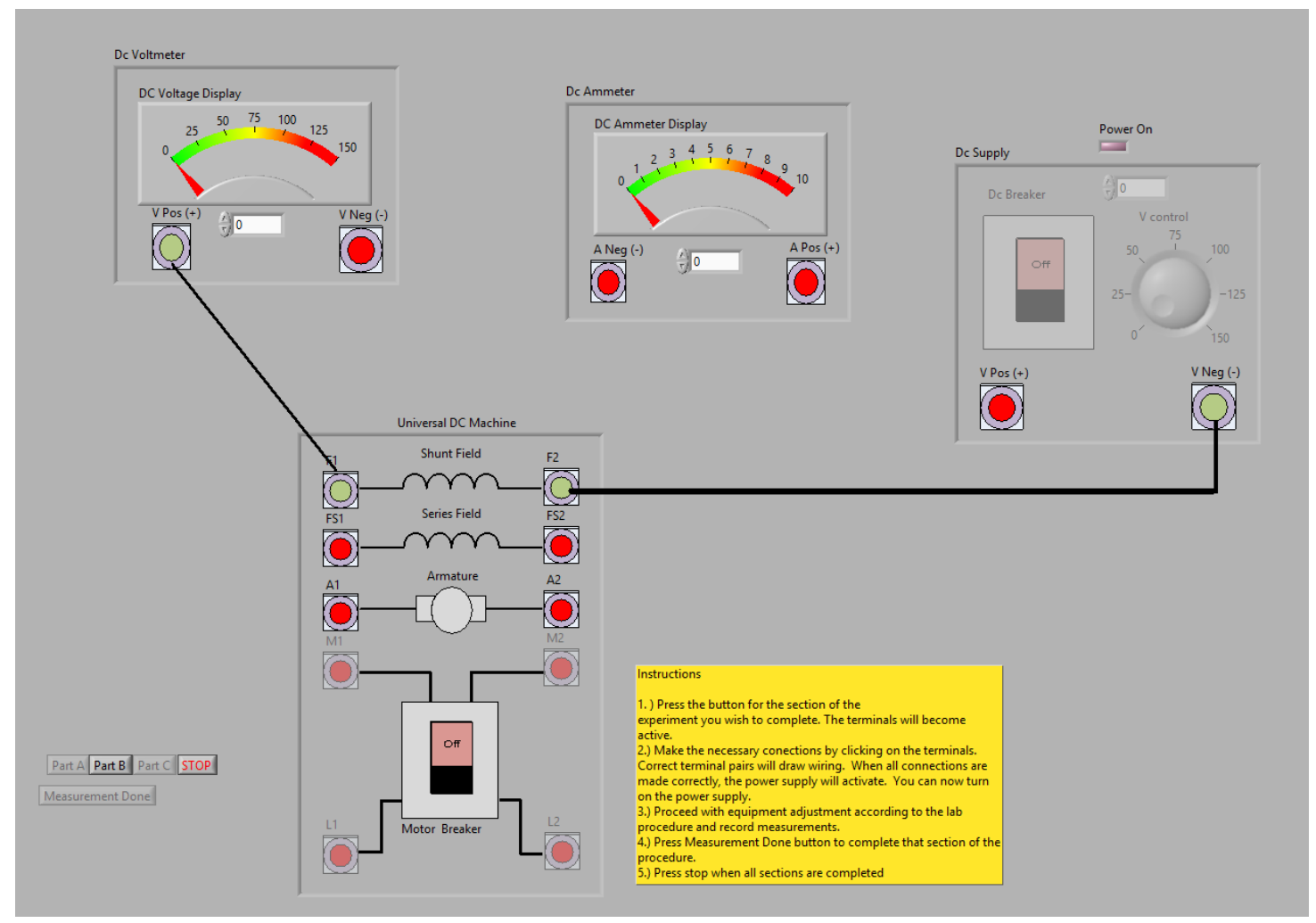

Figure 2. Experiment with Partial Connections. Note: Dc Supply Not Activated.

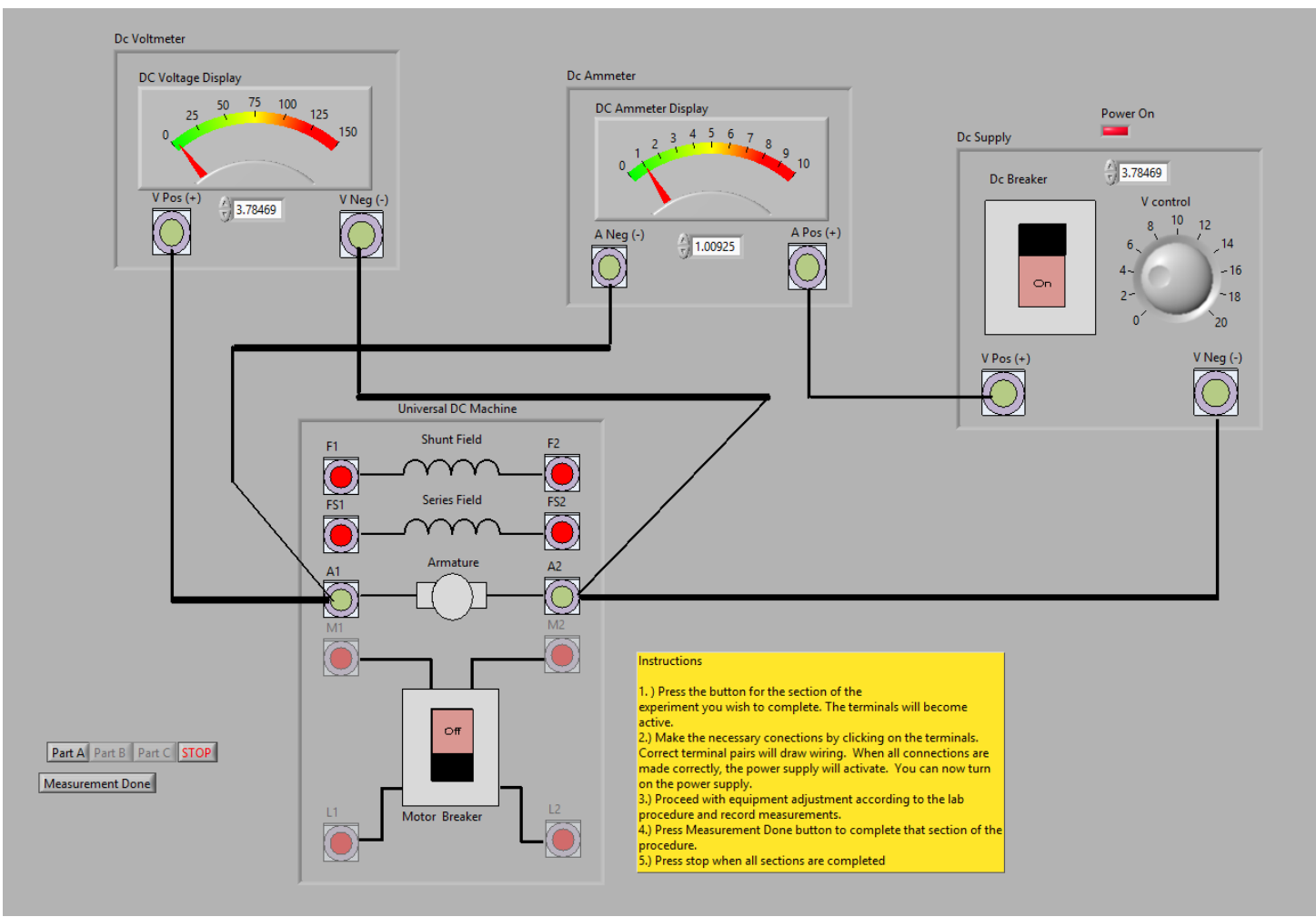

Figure 3. Completed Experimental Connections Showing Power Supply Activated and Turned On. 
The example simulator shown in Figure 1 requires users to select the correct terminal pairs that implement the schematic circuits show in the experimental procedure. Correct selections display a connection between the terminals. A user must complete all the require connections before the power supply is enabled. Figure 2 shows the user interface with connections partially completed. Completing all connections correctly allow users to activate the power switch by turning the power switch on. Just as in the physical system, users must turn on the supply before they can set the output voltage. Figure 3 shows the completed circuit connections with the power supply activated and ready for adjustment.

The development team completed a prototype lab activity to test function and student reaction to the use of simulators instead of lab equipment. The prototype simulator implements a simple experiment in which the students measure field resistances and armature resistance of a dc motor by adjusting a de voltage supply until rated winding/armature current flows. The students then compute the dc resistance from the recorded voltage and current measurements using Ohm's law.

Students must select the button identified with each section of the lab procedure to begin that part of the experiment. This action activates the simulator for connection inputs. After making all required connections and measurements, the user presses the Measurement Completed button to reset the simulator for the other parts of the experiment. After testing and validation, the LabVIEW files are compiled into executable files for installation in the learning management system. Students download this file and can work on the experiments at their own pace without having an Internet connection or waiting until an access becomes available in online simulator products.

The simulator along with additional information is available for download at http://www.engr.siu.edu/techproject. Instruction is provided at the aforementioned URL to guide in the download and installation process.

\section{Survey Results and Discussion}

A pilot group of students gave their evaluation of the simulator and its performances using an online survey instrument. This group had previously conducted the experiment in a face-to-face setting using the actual machines in the on-campus lab facility. Table 1 lists the questions and student responses. The faculty collected information on several factors. One of the survey's main goals was to compare the students' perceptions of the virtual versus real experience. The survey questions also examined the simulator's user friendliness and the extent to which students were able to attain the learning objectives via the simulated experiment. The later was difficult to determine since the group was previously exposed to the lab. Nonetheless, the students' assessment of their own learning provided insight into the pedagogical effectiveness of the simulated lab. The pedagogical effectiveness of simulation is well researched and there is ample 
evidence to prove that students perform, in general, as good in simulated experiences as they do in a physical lab facility.

It was important also to capture the students' suggestions for improvement. Hence, several openended questions were asked pertaining to the simulation software. Table 2 lists these questions and the corresponding responses.

The survey results show that students generally liked the experience of using the simulator and found it convenient. The survey results also show that most of the students, $87.5 \%$, would prefer some combination of the lab hardware and software simulators for an electric machines lab experience. However, it also indicates that $87.5 \%$ indicated that they learn as much or better using the simulator than doing the physical lab. Also, $75 \%$ felt comfortable using the simulator exclusively for all the experiments, while only $12.5 \%$ expressed disagreement to doing this. Our takeaway is blurred since the students impression of their learning experience was skewed by their previous exposure and it is also believed that in time they became more familiar with the theory so naturally they may be inclined to believe that they have learned more. On the other hand, their attitude towards the simulator was surprising. They actually felt comfortable simply using the simulator; indicating that they did not see any significant advantage to doing the labs with actual machines. Again, this is discounted by their response of $100 \%$ agreement to the question, "I would prefer using actual machines in all labs with no simulators". Although of the $100 \%$ only a half $(50 \%)$ expressed strong agreement in comparison to $62.5 \%$ expressing strong agreement to the question, "I would feel satisfied conducting all the labs in this course using the simulator instead of actual machines in the lab".

To get some type of resolution to our queries we did an analysis of the open-ended questions. Concerning critiques of the simulator-students found that the layout of the simulator needed some modifications, as some of the digital readouts were too small to read. Others found the dial indicators difficult to adjust with a mouse. The color scheme could be improved to make the display more attractive and give better contrast. All these issues can be easily corrected using the LabVIEW programming environment. However, one notable comment concerns the complexity of the lab. Some student had concerns as to how this simulator would work for more complex labs with a larger number of connections.

The positive comments include comments on the speed of completion compared to using lab equipment, less work since the machines do not need to be located and mounted on the test bed, and less fear of making incorrect connections and causing damage to machines. Someone indicated that the simulator was a good practice tool but would be best used in conjunction with the existing lab equipment. Based on these findings, the simulator development will continue with the adjustments suggested in from the student survey. 
Table 1- Student Survey Results

Student Survey Results and Comments

\begin{tabular}{|c|c|c|c|c|c|}
\hline Question Text & $\begin{array}{l}\text { Strongly } \\
\text { Agree }\end{array}$ & Agree & $\begin{array}{l}\text { Neither } \\
\text { Agree nor } \\
\text { Disagree } \\
\text { (Neutral) }\end{array}$ & Disagree & $\begin{array}{l}\text { Strongly } \\
\text { Disagree }\end{array}$ \\
\hline $\begin{array}{l}\text { Having an electric motor simulator } \\
\text { for experiments will be more } \\
\text { convenient for me to access and } \\
\text { help me learn the material better. }\end{array}$ & $62.5 \%$ & $25 \%$ & $12.5 \%$ & $0.0 \%$ & $0.0 \%$ \\
\hline $\begin{array}{l}\text { The simulator accurately } \\
\text { represented the physical hardware } \\
\text { used in the lab experiment. }\end{array}$ & $62.5 \%$ & $37.5 \%$ & $0.0 \%$ & $0.0 \%$ & $0.0 \%$ \\
\hline $\begin{array}{l}\text { I would rather use a simulator } \\
\text { similar to this one than use actual } \\
\text { machines in lab. }\end{array}$ & $25 \%$ & $25 \%$ & $37.5 \%$ & $12.5 \%$ & $0.0 \%$ \\
\hline $\begin{array}{l}\text { I would prefer a combination of } \\
\text { hands-on labs and a simulator. }\end{array}$ & $75 \%$ & $12.5 \%$ & $12.5 \%$ & $0.0 \%$ & $0.0 \%$ \\
\hline $\begin{array}{l}\text { I would prefer using actual } \\
\text { machines in all labs with no } \\
\text { simulators. }\end{array}$ & $50 \%$ & $50 \%$ & $0.0 \%$ & $0.0 \%$ & $0.0 \%$ \\
\hline $\begin{array}{l}\text { The simulator was easy to use (User } \\
\text { friendly). }\end{array}$ & $75 \%$ & $25 \%$ & $0.0 \%$ & $0.0 \%$ & $0.0 \%$ \\
\hline $\begin{array}{l}\text { The controls on the simulator were } \\
\text { well positioned and clearly marked. }\end{array}$ & $62.5 \%$ & $37.5 \%$ & $0.0 \%$ & $0.0 \%$ & $0.0 \%$ \\
\hline $\begin{array}{l}\text { Making connections was intuitive } \\
\text { and easily accomplished. }\end{array}$ & $87.5 \%$ & $12.5 \%$ & $0.0 \%$ & $0.0 \%$ & $0.0 \%$ \\
\hline $\begin{array}{l}\text { The simulator performed like the } \\
\text { actual equipment in the lab for this } \\
\text { experiment. }\end{array}$ & $50 \%$ & $50 \%$ & $0.0 \%$ & $0.0 \%$ & $0.0 \%$ \\
\hline $\begin{array}{l}\text { The meters were easy to read and } \\
\text { the controls worked properly. }\end{array}$ & $37.5 \%$ & $62.5 \%$ & $0.0 \%$ & $0.0 \%$ & $0.0 \%$ \\
\hline $\begin{array}{l}\text { I believe I performed the lab as } \\
\text { good as or better using the simulator } \\
\text { than using the actual machines in } \\
\text { the lab. }\end{array}$ & $25 \%$ & $62.5 \%$ & $12.5 \%$ & $0.0 \%$ & $0.0 \%$ \\
\hline $\begin{array}{l}\text { I believe I learn as much or more } \\
\text { from the lab when I used the } \\
\text { simulator than when I use the actual } \\
\text { machines in the lab. }\end{array}$ & $75 \%$ & $12.5 \%$ & $12.5 \%$ & $0.0 \%$ & $0.0 \%$ \\
\hline $\begin{array}{l}\text { I would feel satisfied conducting all } \\
\text { the labs in this course using the } \\
\text { simulator instead of actual machines } \\
\text { in the lab. }\end{array}$ & $62.5 \%$ & $12.5 \%$ & $12.5 \%$ & $12.5 \%$ & $0.0 \%$ \\
\hline
\end{tabular}


Table 2 - Open Ended Question Responses

\begin{tabular}{|c|c|}
\hline Question Text & Responses \\
\hline $\begin{array}{l}\text { What did you like about the } \\
\text { simulator? }\end{array}$ & $\begin{array}{l}\text { It was intuitive and interested me. } \\
\text { Ease of use, easy to see data } \\
\text { Easy to use no trying to get motor and generator into } \\
\text { position no risk of electrocution. } \\
\text { It was very easy to use and there were no troubles with } \\
\text { using the system. } \\
\text { It was easy to use, hard to screw up } \\
\text { easy to use } \\
\text { Its quicker. } \\
\text { Easy to use, convenient, could be done at home }\end{array}$ \\
\hline $\begin{array}{l}\text { What did you dislike about the } \\
\text { simulator? }\end{array}$ & $\begin{array}{l}\text { Nothing, no bells and whistles but program works great } \\
\text { The boxes that showed the digital readout for meters was a } \\
\text { little small. } \\
\text { It took less time then actually using a machine. } \\
\text { It was hard to adjust the voltage to get the desired current. } \\
\text { not sure how it will look with more complicated labs } \\
\text { Colors } \\
\text { turning voltage dial with mouse was hard to get right }\end{array}$ \\
\hline $\begin{array}{l}\text { What can be done to improve the } \\
\text { simulator? }\end{array}$ & $\begin{array}{l}\text { N/A - it worked well } \\
\text { Better wire animations } \\
\text { sound effects and increase size of digital readout } \\
\text { nothing honestly } \\
\text { If possible, improve the resolution of the voltage adjust } \\
\text { wheel. } \\
\text { It's good for now. And do all the stuff that I need plus I dint } \\
\text { have much experience I get to know. } \\
\text { something other than dial to adjust input voltage }\end{array}$ \\
\hline $\begin{array}{l}\text { Please include any other comment } \\
\text { about your experience using the } \\
\text { simulator. }\end{array}$ & $\begin{array}{l}\text { It was a good experience and will help speed up certain } \\
\text { labs. } \\
\text { I like this software. } \\
\text { Quick load and ran good. Where can I get my own copy? } \\
\text { liked it a lot. Maybe increase in the size of the readings and } \\
\text { on the meters. } \\
\text { It was nice to do the lab without the risk of connecting } \\
\text { something wrong. } \\
\text { It is good for practice but still need a physical lab from } \\
\text { time to time to get familiar with the actual equipment } \\
\text { I like the simulator since fast and give me perfect } \\
\text { measures. } \\
\text { overall it was very good }\end{array}$ \\
\hline
\end{tabular}




\section{Conclusion}

The main purpose of this development work was to create a user-friendly simulator that is able to 'mimic' the machines in the physical lab. The analysis of the results from a pilot group of students indicates that the objective has largely been met. Although, there is room for the improvement of the simulator in terms of layout, and its ability to facilitate more complex lab activities. The survey results indicate that a majority of the students are satisfied conducting labs exclusively by the software simulation. Although there are also indications that students may prefer simply using the actual equipment in a lab facility. The analysis of students' perception and the pedagogical effectiveness of the simulator provide evidences that students will be mostly satisfied using the software simulation exclusively to conduct their experiments. However, the pragmatic approach may be to somehow include the flexibility in the curriculum, so that students are provided the opportunity to manipulate the actual machines- to see, hear, touch, and smell these machines in action.

\section{Bibliography}

1. Julio Garcia, Patricia Backer "Assessment of LabVIEW and Multisim In the Delivery of Electronics Laboratory Content", Proceedings of the ASEE Annual Conference and Exposition, Honolulu, Hawaii, June 2007

2. Yacob Astatke, Craig J. Scott, Jumoke O. Ladeji-Osias "Online Delivery of Electrical Engineering Laboratory Courses", Proceedings of the ASEE Annual Conference and Exposition, San Antonio, TX, 2012.

3. Kevin P. Pintong, Douglas H. Summerville, Kyle J. Temkin, "Transitioning a Lab-Based Course to the Online Format, Strategies for Success", Proceedings of the ASEE Annual Conference and Exposition, San Antonio, TX, 2012.

4. Radian Belu, "Virtual Laboratory For Study of the Electric Machines Parameters and Characteristics", Proceedings of the ASEE Annual Conference and Exposition, Louisville, KY, 2010

5. Radian G Belu, Irina Nicoleta Ciobanescu Husanu, "Using a Virtual Platform for Teaching Electrical Machines and Power Systems", Proceedings of the ASEE Annual Conference and Exposition, Atlanta, GA, 2013

6. S. Ayasun and G. Karbeyaz, DC motor speed control methods using MATLAB/Simulink and their integration into undergraduate electric machinery courses, Computer Applications in Engineering Education, vol. 15, 2007, pp. 347 - 354.

7. J.R. Riba-Ruiz, A. G. Espinosa, J.A. Ortega, Validation of the Parametric Model of a DC Contactor Using Matlab/Simulink, Computer Applications in Engineering Education, vol. 17, 2009, pp. 337-346.

8. LabVIEW For Electric Circuits, Machines, Drives, and Laboratories, Nesimi Ertugrul, Prentice Hall PTR, 2002. 